\title{
Obesity and psychological traits associated with eating disorders among Cypriot adolescents: comparison of 2003 and 2010 cohorts
}

\author{
C. Hadjigeorgiou, ${ }^{7}$ M. Tornaritis, ${ }^{1,2}$ S. Savvas, ${ }^{1}$ A. Solea ${ }^{7}$ and A. Kafatos ${ }^{3}$
}

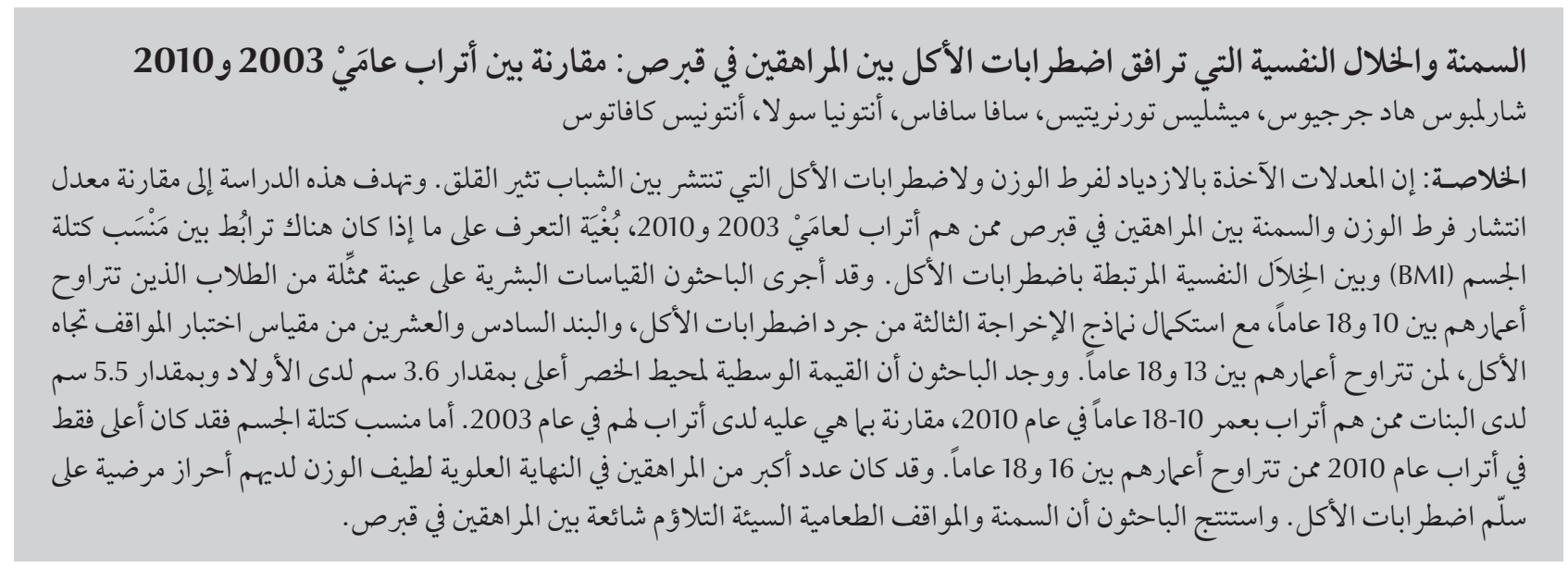

ABSTRACT Increasing rates of overweight and eating disorders among young people are a concern. The aim of this study was to compare the prevalence of overweight/obesity among Cypriot adolescents between cohorts from 2003 and 2010 and to determine whether body mass index (BMI) was associated with psychological traits linked to eating disorders. Anthropometric measures were done on a representative sample of students aged 10-18 years and the Eating Disorder Inventory-3rd version (EDI-3) and 26-item Eating Attitudes Test (EAT-26) scales were completed by 13-18-year-olds. Mean waist circumference of the 2010 cohort of 10-18-year-olds was $3.6 \mathrm{~cm}$ higher in boys and $5.5 \mathrm{~cm}$ higher in girls than the 2003 cohort. Mean BMI was higher in 2010 only in the 16-18-year-old age group. More adolescents on the higher end of the weight spectrum had pathological scores on the eating disorder scales. Obesity and maladaptive eating attitudes are common in Cypriot adolescents.

Obésité et caractéristiques psychologiques associées aux troubles alimentaires chez les adolescents chypriotes : comparaison des cohortes de 2003 et de 2010

RÉSUMÉ Les taux croissants des troubles alimentaires et de surpoids chez les jeunes sont préoccupants. L'objectif de la présente étude était de comparer la prévalence du surpoids et de l'obésité chez les adolescents chypriotes des cohortes de 2003 et 2010 et de savoir si l'indice de masse corporelle était associé à des caractéristiques psychologiques liés aux troubles alimentaires. Des mesures anthropométriques ont été prises au sein d'un échantillon représentatif d'élèves âgés de 10 à 18 ans. Les adolescents de 13 à 18 ans ont rempli la troisième version de l'échelle Eating Disorder Inventory-3 et ont passé le test en 26 items Eating Attitudes Test. Le tour de taille moyen de la cohorte de 2010 chez les élèves de 10 à 18 ans était supérieur de 3,6 cm chez les garçons et de 5,5 cm chez les filles par rapport à la cohorte de 2003. L'indice de masse corporelle moyen était plus élevé en 2010 uniquement dans le groupe des adolescents de 16 à 18 ans. Les jeunes dont le poids était situé à la limite supérieure de la fourchette étaient plus nombreux à obtenir des résultats pathologiques aux échelles sur les troubles alimentaires. L'obésité ainsi que des conduites alimentaires inadaptées sont fréquentes chez les adolescents chypriotes. 


\section{Introduction}

The World Health Organization considers obesity to be a global epidemic [1] and children too are becoming overweight at increasingly younger ages $[2,3]$. Increases in the prevalence of eating disorders have also been noted [4]. Obesity has been identified as one of the risk factors for the development and maintenance of eating disorder symptoms [5] and pathological body dissatisfaction [6] in adolescence. Furthermore, research has indicated that eating disorders and obesity share common risk factors including dieting, body dissatisfaction, teasing and weight stigmatization, poor nutrition and physical inactivity [7].

One of the first prevalence studies of obesity using a representative sample of Cypriot children 6-17 years of age dates back to the academic year 199900 , when it was found that $25.7 \%$ of boys and $22.7 \%$ of girls were overweight or obese according to the International Obesity Task Force definition [8]. While no epidemiological data exist on Cypriot adolescents' eating behaviours and attitudes, the general consensus among the paediatric medicine community is that eating disorders are being diagnosed more frequently than before. The present study was carried out in view of the very limited literature on body mass index (BMI) of Cypriot adolescents $[8,9]$ and the complete lack of literature on eating behaviours and attitudes of this group. In addition, given that no long-term, systematic interventions have taken place in Cypriot schools for either obesity or eating disorders it was hoped that with accurate figures on prevalence rates and how these have changed over a period of 8 years will inform and perhaps encourage the authorities to take more direct and noteworthy action.

The aims of the current study were to investigate the prevalence of overweight and obesity among Cypriot adolescents, to determine if there have been changes over an 8-year period and to check the associations between $\mathrm{BMI}$ and the psychological correlates of eating disorders for both sexes.

\section{Methods}

The present study was part of a large cross-sectional survey performed in Cyprus at 2 time periods, 2003 and 2010, using 2 different cohorts. The study was designed to investigate the eating attitudes and behaviours of adolescents in Cyprus. The surveys in both years took place in elementary and secondary schools.

\section{Sample}

In the years 2003 and 2010 representative samples of students was selected with the help of the statistical service of the Ministry of Finance in Cyprus. The selection was based on the distribution of the total population with regard to district and area of residence. A multistage sampling procedure was used. Classes per grade of elementary and secondary schools in each district were assigned numbers from which classes were randomly selected. In 2003, a total of 15 classes from 15 different elementary schools and a total of 78 classes from 54 secondary schools were included in the study. The number of students per selected class was 8-28 depending on the size of the districts. It was estimated that 1600 students aged 11-18 years would satisfy the needs of the survey. A total of 2017 students participated, 1062 females and 950 males (5 students did not state their sex) with a mean age 14.4 [standard deviation (SD 2.1) years]. Thirty students were absent on the day of testing and so did not take part in the study and 13\% of parent refused to allow their children to take part. In 2010, a total of 22 classes from 22 different elementary schools and 135 classes from 45 different secondary schools were included. A total of 2302 students, 1315 females and
987 males took part in the study, with a mean age of 14.1 (SD) 2.3 years]. Eleven students were absent on the day of testing and $12 \%$ of parents refused participation. In the analyses data were used only from those students with complete measurements and the data were accumulated. There was no reason to assume any significant difference in the characteristics of participants and non-participants since both in 2003 and 2010 participants were not aware beforehand of the research topic.

\section{Data collection}

Informed consent was received from the students' parents. Participation in the study was voluntary and students were assured about the confidentiality of their answers.

Anthropometric characteristics (weight, height and waist circumference) were measured by trained professionals for the whole sample of students aged 10-18 years. All anthropometric measures were taken in the morning, using Seca measuring instruments, by the same trained professional.

Students aged 13 years and above were then given 2 questionnaires, the 26-item Eating Attitudes Test (EAT26) $[10]$ and the Eating Disorder Inventory, 3rd version (EDI-3) [11] to complete at school. Both questionnaires were reproduced with permission. All students at a given school filled out the questionnaires simultaneously under the supervision of a trained professional. Those participants who did not state their sex and age were excluded from the statistical analyses. In addition, in the statistical analyses only those students with complete responses to scale items on the questionnaires were included.

\section{Measures}

The EAT-26 is a self-report questionnaire of 26 items assessing the range of symptoms of anorexia and bulimia nervosa. Each item is rated on a 6-point Likert scale ranging from never to always. 
Responses are then assigned a score from 0-3 with non-symptomatic answers (sometimes, rarely, never) given a score of 0 ; and symptomatic answers (always, usually, often) scored 3, 2, and 1 respectively. Total EAT scores (the sum of all 26 items) were calculated for each participant. The clinical cut-off point for eating disturbances is a score of 20 or above, which is indicative of serious eating disturbances or weight concerns. Previous validations of the EAT-26 have found good reliability scores across studies ranging from 0.79 to 0.94 [12]. In this study the alpha coefficient was found to be 0.77 . The EAT-26 items form 3 subscales: (a) dieting, measuring an avoidance of fatty foods and preoccupation with losing weight; (b) bulimia and food preoccupation, items of which indicate bulimic tendencies; (c) oral control, relating to perceived external pressures to gain weight and self-control of eating [10]. The subscale scores were computed by adding all items belonging to the particular scale.

The EDI-3 is also a self-report questionnaire consisting of 91 items measuring psychological domains relevant to the understanding and treatment of eating disorders. It is intended mainly for individuals 13 years of age and older. The EDI-3 presents items on a 6-point Likert scale using a $0-4$ point scoring system (e.g. 001234) with null scores for the non-symptomatic answers. The 91 items of the questionnaire are organized into 12 primary scales: 3 eating-disorder specific scales and 9 general psychological scales relevant but not specific to eating disorders [11]. The 3 eating disorder specific scales relevant to this research were: (a) drive for thinness, which consisted of 7 items measuring an individual's preoccupation with dieting and fear of weight gain; (b) bulimia, which comprised 8 items and assesses an individual's tendency to think about and engage in periods of overeating; and (c) body dissatisfaction scale, which consists of 10 items assessing the extent of people's dissatisfaction with the overall shape and size of their body. Raw scores were calculated for each of these scales and using the EDI-3 interpretive guidelines cut-off points were created. Reliability scores for the 3 eating disorder risk scales were found to be in the high 0.80 s to low 0.90 s across normative groups. In this study the Cronbach alpha coefficient for the drive for thinness, bulimia and body dissatisfaction scales were 0.76 , 0.62 and 0.86 respectively. The low self-esteem scale was also calculated for each participant to assess negative self-evaluation. Most theories consider low self-esteem to play a crucial role in the development and maintenance of eating disorders $[11,13]$.

\section{Statistical analyses}

Descriptive statistics including mean and standard deviation (SD), frequencies and percentages were conducted using SPSS, version 18.0 statistical software. As height and weight may differ among boys and girls, especially as they increase in age, separate analyses were made for each sex. For all analyses $\alpha<$ 0.05 was taken as statistically significant difference between groups.

Independent sample $t$-tests were performed to assess differences between participants in 2003 and 2010. Adolescents were divided into 4 categorical groups (underweight, normal, overweight and obese) according to their BMI, using age- and sex appropriate cutoff points in line with Cypriot percentile curves [9]. Chi-squared tests were used to determine whether there were any differences between the results for the years 2003 and 2010 in the overweight and obese categories. The data were analysed separately in 3 age groups (10-12, 13-15 and 16-18 years) since children differ in maturational level (pre-, early- and late adolescence) and their level of physical development at these ages.

The 13-18-year-olds completed the questionnaires EAT-26 and EDI-3 and the 2 age groups were collapsed into one for the following statistical analyses. Participants' scores on the EAT-26 and the EDI-3 subscales of drive for thinness, bulimia, body dissatisfaction and low self-esteem were divided into normal and pathological scores in accordance with the EDI-3 interpretive guidelines [11]. Chi-squared tests were subsequently used to compare BMI category and scores on the EAT-26 and EDI-3 subscales for both males and females. Graphical representations of mean total scores on the scales for each BMI category were conducted to facilitate result interpretation. Lastly, partial correlations were carried out, controlling for the effects of age and year of testing, to explore the relationship between BMI and EAT-26, EDI-3 subscales.

\section{Results}

Descriptive statistics on BMI and waist circumference for the years 2003 and 2010 are presented in Table 1 for each sex and age group separately. The waist circumference of both boys and girls of all age groups was significantly higher in 2010 compared with 2003. BMI was also significantly higher in 2010 for the $16-18$ year age groups by $0.77 \mathrm{~kg} / \mathrm{m}^{2}$ for girls and $0.94 \mathrm{~kg} / \mathrm{m}^{2}$ for boys.

Table 2 shows the percentage of adolescents in the 4 BMI categories (underweight, normal, overweight and obese) and the results of the chisquared tests comparing the years 2003 and 2010. No significant differences in BMI were noted between the years 2003 and 2010 for the 10-12 year-old age group. However, for the 13-15-year-olds significantly fewer were in the overweight and obese categories in 2010 compared with 2003, whereas the opposite was true for 16-18 year old males and females; the percentage of 16-18 year-old adolescents in the obese category was almost twice as high in 2010. 


\begin{tabular}{|c|c|c|c|c|c|c|}
\hline \multirow[t]{3}{*}{ Sex/age group } & \multicolumn{3}{|c|}{2003} & \multicolumn{3}{|c|}{2010} \\
\hline & & BMI & WC & & BMI & WC \\
\hline & No. & Mean (SD) & Mean (SD) & No. & Mean (SD) & Mean (SD) \\
\hline \multicolumn{7}{|l|}{ Females } \\
\hline $10-12$ years & 160 & $19.4(3.7)$ & $65.7(9.4)$ & 267 & $19.4(4.0)$ & $69.7(10.5)^{* * *}$ \\
\hline $13-15$ years & 230 & $21.1(3.8)$ & $69.8(9.0)$ & 277 & $20.7(3.3)$ & $73.8(8.5)^{* *}$ \\
\hline 16-18 years & 281 & $21.6(3.3)$ & $69.6(8.3)$ & 303 & $22.4(4.0)^{*}$ & $78.2(10.9)^{* * *}$ \\
\hline \multicolumn{7}{|l|}{ Males } \\
\hline $10-12$ years & 142 & $19.4(3.7)$ & $67.7(10.4)$ & 237 & $19.9(4.0)$ & $70.7(11.0)^{*}$ \\
\hline 13-15 years & 225 & $21.1(3.8)$ & $72.9(10.2)$ & 247 & $21.4(4.1)$ & $76.7(11.3)^{* * *}$ \\
\hline 16-18 years & 215 & $22.5(3.2)$ & $76.5(7.5)$ & 167 & $23.4(3.6)^{*}$ & $80.5(9.6)^{* * *}$ \\
\hline
\end{tabular}

Independent sample t-test comparing the participants in the years 2003 and 2010 : ${ }^{*} P<0.05 ;{ }^{*} P<0.01 ;{ }^{* *} P<0.001$. $S D=$ standard deviation .

Tables 3 and 4 reveal the results of the chi-squared tests comparing participants' weight status and their scores (normal or pathological) on the EAT-26 and EDI-3 subscales. The participants in the years 2003 and 2010 were merged for the analyses. For both males and females the percentage of those having pathological scores on the questionnaires increased with higher weight categories. The only exception was that no significant difference was found for the low self-esteem subscale in male participants.

Figure 1 shows the mean total scores for the EAT-26 and the drive for thinness, bulimia and body dissatisfaction subscales of the EDI-3 by BMI category in both sexes. For both males and females higher mean total scores were seen progressing from the underweight to obese BMI category. Mean total scores on all scales were lower for males than females.

Partial correlations between BMI and EDI-3 and EAT-26 subscales were conducted for both males and females. Since the results of the previous chi-squared tests merged the participants of both 2003 and 2010, and took into account all adolescents aged 13-18 years, the partial correlations (Table 5) controlled for both the effects of age and cohort year. The results confirm that in females there were strong positive correlations between BMI and all scales, with the exception of low self-esteem of the EDI-3. Adolescent males also had strong positive correlations between BMI and questionnaire scales, apart from the low self-esteem and bulimia subscales of the EAT-26.

\section{Discussion}

The results of the present study add to our knowledge on eating disorders and their links to BMI among the Cypriot adolescent population. The prevalence of overweight was higher in the 2010 cohort of Cypriot youth than the 2003 cohort and the prevalence of

\begin{tabular}{|c|c|c|c|c|c|c|c|c|c|c|c|c|c|c|c|}
\hline \multirow[t]{3}{*}{ Sex/BMI group } & \multicolumn{5}{|c|}{ 10-12 years } & \multicolumn{5}{|c|}{ 13-15 years } & \multicolumn{5}{|c|}{ 16-18 years } \\
\hline & \multicolumn{2}{|c|}{2003} & \multicolumn{2}{|c|}{2010} & \multirow[t]{2}{*}{$x^{2}$} & \multicolumn{2}{|c|}{2003} & \multicolumn{2}{|c|}{2010} & \multirow[t]{2}{*}{$x^{2}$} & \multicolumn{2}{|c|}{2003} & \multicolumn{2}{|c|}{2010} & \multirow[t]{2}{*}{$x^{2}$} \\
\hline & No. & $\%$ & No. & $\%$ & & No. & $\%$ & No. & $\%$ & & No. & $\%$ & No. & $\%$ & \\
\hline \multicolumn{16}{|l|}{ Females } \\
\hline Underweight & 20 & 12.5 & 27 & 10.1 & 1.70 & 19 & 8.3 & 21 & 7.6 & $6.79 *$ & 40 & 14.2 & 33 & 10.9 & $10.69^{* * *}$ \\
\hline Normal & 94 & 58.8 & 149 & 55.8 & & 151 & 65.7 & 209 & 75.5 & & 199 & 70.8 & 193 & 63.5 & \\
\hline Overweight & 34 & 21.3 & 70 & 26.2 & & 50 & 21.7 & 40 & 14.4 & & 33 & 11.7 & 62 & 20.4 & \\
\hline Obese & 12 & 7.5 & 21 & 7.9 & & 10 & 4.3 & 7 & 2.5 & & 9 & 3.2 & 16 & 5.3 & \\
\hline \multicolumn{16}{|l|}{ Males } \\
\hline Underweight & 10 & 7.0 & 16 & 6.8 & 4.88 & 16 & 7.1 & 11 & 4.5 & 4.20 & 7 & 3.2 & 8 & 4.8 & $6.65^{*}$ \\
\hline Normal & 94 & 66.2 & 132 & 55.7 & & 140 & 62.2 & 169 & 68.4 & & 159 & 73.3 & 103 & 61.7 & \\
\hline Overweight & 26 & 18.3 & 64 & 27 & & 52 & 23.1 & 44 & 17.8 & & 45 & 20.7 & 46 & 27.5 & \\
\hline Obese & 12 & 8.5 & 25 & 10.5 & & 17 & 7.6 & 23 & 9.3 & & 6 & 2.8 & 10 & 6.0 & \\
\hline
\end{tabular}

Chi-squared tests comparing participants in the years 2003 and 2010 : ${ }^{*} P<0.05$; ${ }^{* *} P<0.001$. 


\begin{tabular}{|c|c|c|c|c|c|c|c|c|c|}
\hline \multirow[t]{2}{*}{ Variable } & \multicolumn{2}{|c|}{ Underweight } & \multicolumn{2}{|c|}{ Normal } & \multicolumn{2}{|c|}{ Overweight } & \multicolumn{2}{|c|}{ Obese } & \multirow[t]{2}{*}{$x^{2}$} \\
\hline & No. & $\%$ & No. & $\%$ & No. & $\%$ & No. & $\%$ & \\
\hline \multicolumn{10}{|l|}{ EAT-26 } \\
\hline Normal score & 78 & 81.3 & 469 & 70.3 & 75 & 49.0 & 17 & 37.8 & \multirow{2}{*}{$51.38^{* * *}$} \\
\hline Pathological score $(>20)$ & 18 & 18.8 & 198 & 29.7 & 78 & 51.0 & 28 & 62.2 & \\
\hline \multicolumn{10}{|l|}{ Drive for thinness } \\
\hline Normal score & 115 & 91.3 & 610 & 76.6 & 115 & 62.2 & 20 & 44.4 & \multirow{2}{*}{$56.99^{* * *}$} \\
\hline Pathological score $(\geq 17)$ & 11 & 8.7 & 186 & 23.4 & 70 & 37.8 & 25 & 55.6 & \\
\hline \multicolumn{10}{|l|}{ Bulimia } \\
\hline Normal score & 101 & 75.4 & 545 & 66.9 & 109 & 57.7 & 24 & 51.1 & \multirow{2}{*}{$15.94^{* * *}$} \\
\hline Pathological score $(\geq 5)$ & 33 & 24.6 & 270 & 33.1 & 80 & 42.3 & 23 & 48.9 & \\
\hline \multicolumn{10}{|l|}{ Body dissatisfaction } \\
\hline Normal score & 127 & 98.4 & 609 & 77.0 & 84 & 46.7 & 15 & 30.6 & \multirow{2}{*}{$155.53^{* * *}$} \\
\hline Pathological score $(\geq 22)$ & 2 & 1.6 & 182 & 23.0 & 96 & 53.3 & 34 & 69.4 & \\
\hline \multicolumn{10}{|l|}{ Low self-esteem } \\
\hline Normal score & 105 & 83.3 & 636 & 80.0 & 146 & 78.9 & 32 & 69.6 & \multirow{2}{*}{$4.07^{*}$} \\
\hline Pathological score $(\geq 9)$ & 21 & 16.7 & 159 & 20.0 & 39 & 21.1 & 14 & 30.4 & \\
\hline
\end{tabular}

Chi-squared tests: ${ }^{*} P<0.05 ;{ }^{* *} P<0.001$.

pathological eating attitudes among adolescents increased with higher BMI.

One of the findings that stand out regarding Cypriot youth is that across all age groups waist circumference was higher in 2010 in comparison with
2003, a finding that held true for both males and females. Waist circumference is an important indicator of abdominal fat distribution [9]. Abdominal fat distribution has been linked to a number of health risks including cardiovascular disease [14,15], insulin resistance, type 2 diabetes, dyslipidaemia and more [16]. There was no reason to assume that methodological differences accounted for these observations since waist measurement was defined identically over the 2 time periods and measured by the same individuals. Waist circumference

\begin{tabular}{|c|c|c|c|c|c|c|c|c|c|}
\hline \multirow[t]{2}{*}{ Scale } & \multicolumn{2}{|c|}{ Underweight } & \multicolumn{2}{|c|}{ Normal } & \multicolumn{2}{|c|}{ Overweight } & \multicolumn{2}{|c|}{ Obese } & \multirow[t]{2}{*}{$x^{2}$} \\
\hline & No. & $\%$ & No. & $\%$ & No. & $\%$ & No. & $\%$ & \\
\hline \multicolumn{10}{|l|}{ Total EAT-26 } \\
\hline Normal score & 34 & 77.3 & 450 & 84.4 & 122 & 76.3 & 34 & 66.7 & \multirow{2}{*}{$13.72^{*}$} \\
\hline High score $(>20)$ & 10 & 22.7 & 83 & 15.6 & 38 & 23.8 & 17 & 33.3 & \\
\hline \multicolumn{10}{|l|}{ Drive for thinness } \\
\hline Normal score & 45 & 97.8 & 583 & 95.4 & 168 & 84.4 & 52 & 77.6 & \multirow{2}{*}{$45.52^{* * *}$} \\
\hline High score $(\geq 17)$ & 1 & 2.2 & 28 & 4.6 & 31 & 15.6 & 15 & 22.4 & \\
\hline \multicolumn{10}{|l|}{ Bulimia } \\
\hline Normal score & 40 & 83.3 & 468 & 74.4 & 137 & 66.5 & 38 & 58.5 & \multirow{2}{*}{$13.87^{* * *}$} \\
\hline High score $(\geq 5)$ & 8 & 16.7 & 161 & 25.6 & 69 & 33.5 & 27 & 41.5 & \\
\hline \multicolumn{10}{|l|}{ Body dissatisfaction } \\
\hline Normal score & 46 & 95.8 & 581 & 97.2 & 155 & 79.1 & 33 & 51.6 & \multirow{2}{*}{$166.2^{* * *}$} \\
\hline High score $(\geq 22)$ & 2 & 4.2 & 17 & 2.8 & 41 & 20.9 & 31 & 48.4 & \\
\hline \multicolumn{10}{|l|}{ Low self-esteem } \\
\hline Normal score & 42 & 87.5 & 534 & 85.9 & 178 & 85.2 & 52 & 78.8 & \multirow{2}{*}{2.57} \\
\hline High score $(\geq 9)$ & 6 & 12.5 & 88 & 14.1 & 31 & 14.8 & 14 & 21.2 & \\
\hline
\end{tabular}

Chi-squared tests: ${ }^{*} P<0.05 ;{ }^{* *} P<0.001$. 
a) Total EAT-26 ( $\boldsymbol{n}=788$ males; $\boldsymbol{n}=960$ females $)$

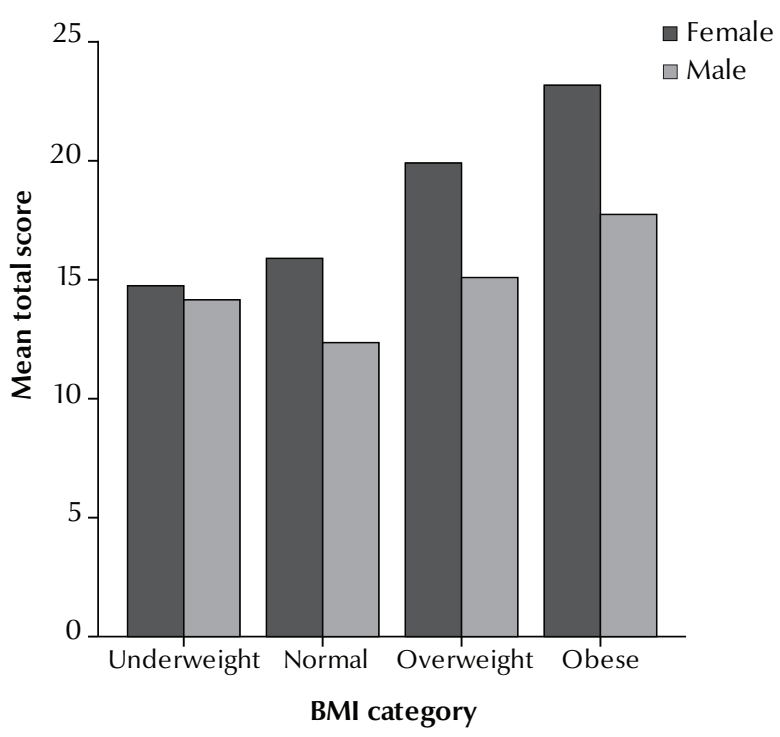

c) Bulimia ( $n=948$ males; $n=1182$ females)

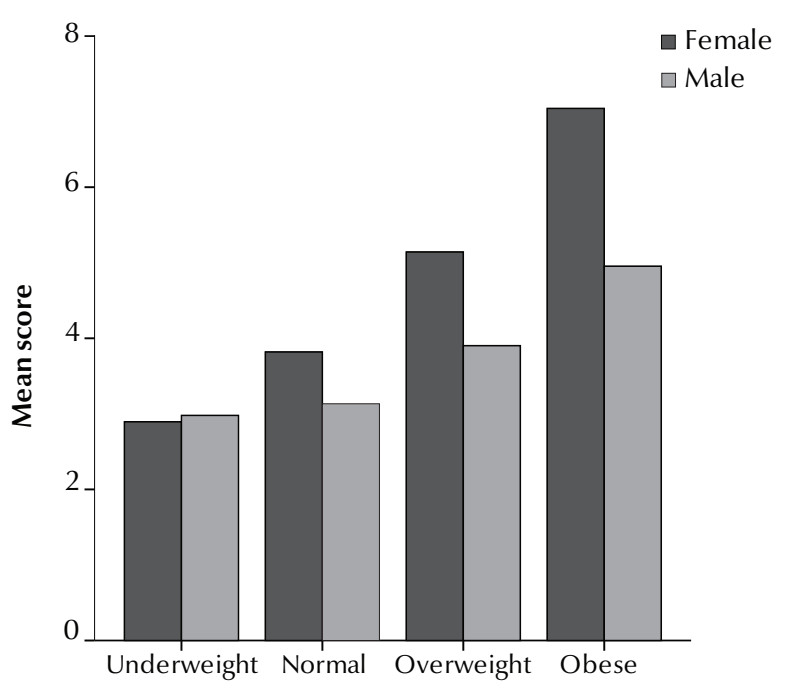

BMI category b) Drive for thinness ( $n=923$ males; $n=1148$ females)

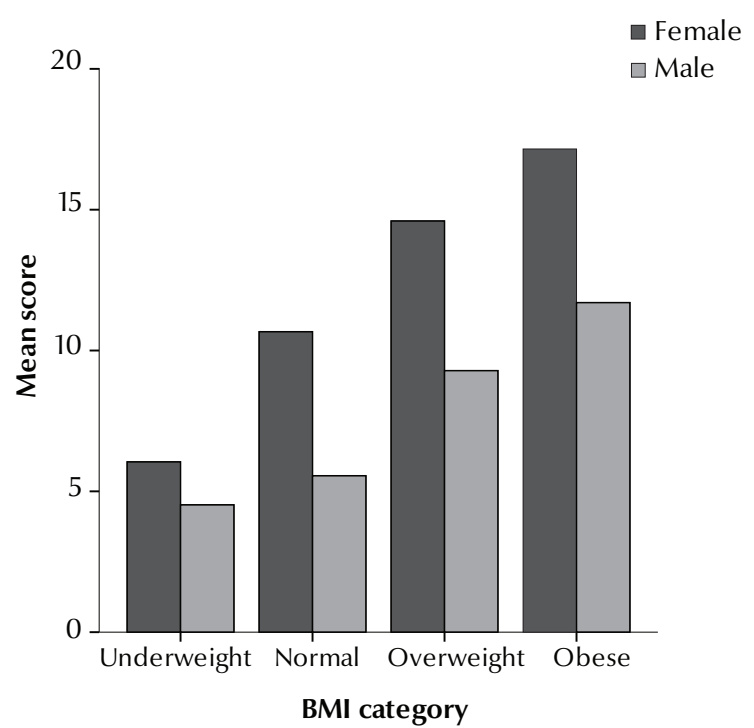

d) Body dissatisfaction ( $n=906$ males; $n=1147$ females)

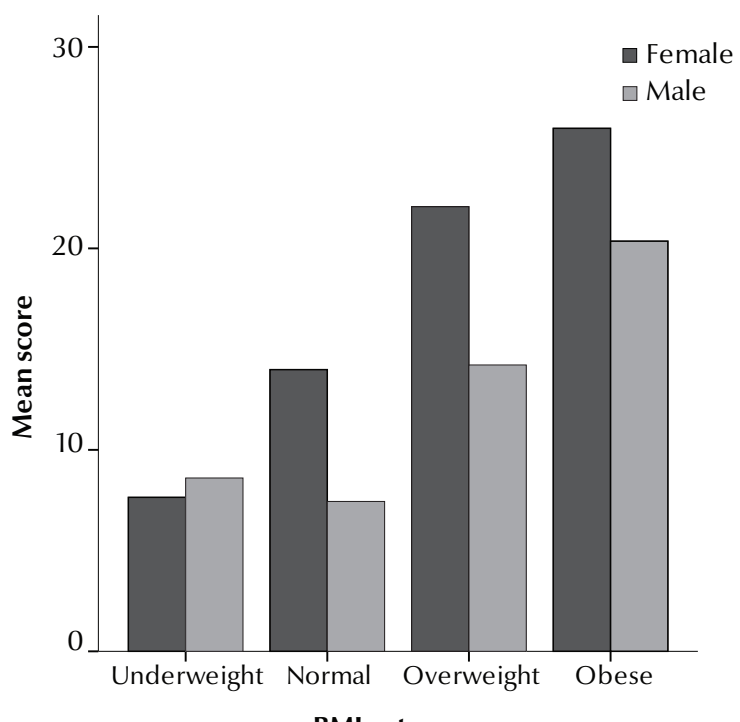

BMI category

Figure 1 Mean scores on the total Eating Attitudes Test (EAT-26) questionnaire and 3 subscales of the Eating Disorder Inventory-3 (EDI-3) by body mass index (BMI) category for both sexes (2003 and 2010 cohorts combined)

and wait-to-height ratio in Cypriot children was measured in 2000 and showed that the average waist circumference was $70.7 \mathrm{~cm}$ for both 10-14-year-old boys and girls alike [15]. The average waist circumferences for the same age groups in 2003 and 2010 were higher than this figure. Increases in waist circumference and the wider problem of childhood obesity have been linked to unhealthy dietary habits and sedentary lifestyles [17]. Studies in Cyprus confirm that children appear to be drawn to sedentary activities $[17,18]$. More specifically, television viewing times far exceeded the 2 hours per day recommended by the American Academy of Pediatrics [18]. Unfortunately we found no study that has looked at how Cypriot adolescents' activity levels have changed over the years.

The biggest difference in waist circumference between the 2 cohorts was among the older adolescent age group; waist circumference was 8.6 $\mathrm{cm}$ and $4.0 \mathrm{~cm}$ higher in $2010 \mathrm{com}$ pared with 2003 in 16-18 year old girls and boys respectively. In addition, higher was BMI observed only among this age group. The percentage of 16-18-year-olds in the overweight/ obese BMI categories was 10.0\% higher for males and $10.8 \%$ higher for females in 2010 versus 2003. Despite the difference in waist circumference among 10-15-year-olds between 


\begin{tabular}{|c|c|c|}
\hline \multicolumn{3}{|c|}{$\begin{array}{l}\text { Table } 5 \text { Correlations of body mass index (BMI) with scores on the the Eating } \\
\text { Disorder Inventory-3 (EDI-3) subscales and total scores on the Eating Attitudes } \\
\text { Test (EAT-26) and its subscales after controlling for the effects of age and cohor } \\
\text { year in male and female adolescents }\end{array}$} \\
\hline \multirow[t]{2}{*}{ Scale } & \multicolumn{2}{|c|}{ Correlation coefficient } \\
\hline & Females & Males \\
\hline \multicolumn{3}{|l|}{ EDI-3 } \\
\hline Drive for thinness & $0.387^{* * *}$ & $0.403^{* * *}$ \\
\hline Bulimia & $0.167^{* * *}$ & $0.145^{* * *}$ \\
\hline Body Dissatisfaction & $0.518^{* * *}$ & $0.520^{* * *}$ \\
\hline Low self-esteem & 0.022 & 0.057 \\
\hline \multicolumn{3}{|l|}{ EAT-26 } \\
\hline Total EAT-26 & $0.214^{* * *}$ & $0.215^{* * *}$ \\
\hline Dieting & $0.392^{* * *}$ & $0.386^{* * *}$ \\
\hline Bulimia & $0.152^{* * *}$ & 0.071 \\
\hline Oral control & $-0.301^{* * *}$ & $-0.192^{* * *}$ \\
\hline
\end{tabular}

${ }^{* * *} P<0.001$.

the 2 time periods, no corresponding differences in BMI were found. Furthermore among the 13-15-yearolds there was a higher percentage of students in the normal BMI category and a lower percentage in the overweight category in 2010 versus 2003. These differences between the groups can perhaps be attributed to changes in physical activity and sedentary behaviour during adolescence. Longitudinal research and investigations of secular trends of physical activity in other countries have shown that the level of moderate to vigorous physical activity decreases as children progress from early to late adolescence, with leisure-time computer use increasing dramatically [19].

BMI is undoubtedly linked to eating attitudes and behaviours, although it seems from our study that the mechanisms may operate differently in boys and girls. In female adolescents aged 13-18 years the percentage of participants within their BMI category scoring in the pathological range on the EAT-26 and eating-disorder specific scales of the EDI-3 increased across $\mathrm{BMI}$ categories, i.e. from underweight to obese. This association was also confirmed when BMI was correlated with these scales. On 2 scales, however, the total EAT-26 and the body dissatisfaction subscale, adolescent males did not follow this pattern; the percentage of participants with pathological scores that the underweight category. Body dissatisfaction among girls is often manifested by concerns about weight loss, whereas for boys body image issues are directed towards increasing weight and developing muscularity [20]. Therefore, unlike females who wish to be thinner, underweight, skinny adolescent boys wish to be bigger and so have higher pathological scores on relevant questionnaire scales in comparison with those of normal weight.

It comes as no surprise that the majority of overweight and obese females in our survey had pathological scores on the drive for thinness scale, as this has been shown to correlate with body weight, and unusually high scores are expected for people who are overweight [11]. What is more concerning are the $8.7 \%$ of underweight and $23.4 \%$ of normal weight adolescent females who had a pathological score on the drive for thinness scale. Drive for thinness has been acknowledged as one of the risk factors for the future development of eating disorders including anorexic were in fact lower in the normal BMI and bulimic symptoms $[11,21,22]$. An even greater number of underweight and normal BMI female adolescents had pathological scores on the bulimia scale than they did on the drive for thinness scale. Research has confirmed that binge-eating is common in individuals who do not meet the criteria of an eating disorder [11], but it also perhaps reflects how binge-eating behaviours are more widely adopted and accepted by the Cypriot adolescent population. Pathological scores on the body dissatisfaction scale reflect unhappiness with body shape and weight as well as discontentment with specific body areas including stomach, thighs and hips [11]. It is positively correlated to body weight which explains why almost 70\% of obese adolescents were dissatisfied with their body in this study. Low selfesteem was found to have no correlation with BMI in our study.

Overall, this research has highlighted a number of important issues with regards to Cypriot youth. By examining trends in BMI alone without considering waist circumference would mean that shifts from muscle to fat would fail to be identified among the younger age groups [23]. It is not possible yet to assess the impact of the increases in waist circumference and BMI on current and future morbidity in the Cypriot population but it is certainly cause for concern. Overweight and obese Cypriot adolescents were shown to have abnormal eating attitudes and behaviours, but the same was true for a smaller percentage of under- and normal-weight youngsters who must not be ignored.

In conclusion, there is a great need for systematic and consistent interventions to take place in Cypriot schools concerning obesity and eating disorders. It is suggested that interventions could target both obesity and eating disorders simultaneously, highlighting to adolescents the importance of physical activity, the significance of having a balanced and healthy diet, the 
consequences of constantly trying to lose weight using harmful methods and the detrimental outcomes of having maladaptive eating behaviours.

\section{Acknowledgements}

Special thanks to Andreas Charalambous, Director of the Pedagogical
Institute, the supervisors, Eva Neofytou and Sandri Taliadorou, and teachers of the Home Economics of the Ministry of Education and Culture.

\section{References}

1. Physical status: the use and interpretation of anthropometry. Geneva, World Health Organization, 1995.

2. Rössner S. Obesity: the disease of the twenty-first century. International Journal of Obesity and Related Metabolic Disorders, 2002, 26(Suppl. 4):S2-S4.

3. Baker JL, Olsen LW, Sørensen TIA. Childhood body-mass inf dex and the risk of coronary heart disease in adulthood. New England Journal of Medicine, 2007, 357:2329-2337.

4. Bungum TJ, Lofton S. The association of body mass index, perceived body mass index, and predictors of eating disorders among a sample of college students. American Journal of Health Education, 2003, 34:6.

5. Fan $\mathrm{Y}$ et al. Associations between body mass index, weight control concerns and behaviors, and eating disorder symptoms among non-clinical Chinese adolescents. BMC Public Health, 2010, 10:314.

6. Beato-Fernández $L$ et al. Risk factors for eating disorders in adolescents. A Spanish community-based longitudinal study. European Child and Adolescent Psychiatry, 2004, 13:287-294.

7. Smith JP. Shared risk factors for youth obesity and disordered eating. Washington DC, American Psychological Association, Public Interest Government Relations Office, 2008.

8. Savva SC et al. Obesity in children and adolescents in Cyprus. Prevalence and predisposing factors. International Journal of Obesity and Related Metabolic Disorders, 2002, 26:1036-1045.

9. Savva SC et al. Reference growth curves for Cypriot children 6 to 17 years of age. Obesity Research, 2001, 9:754-762.

10. Garner DM et al. The Eating Attitudes Test: psychometric features and clinical correlates. Psychological Medicine, 1982, 12:871-878.

11. Garner DM. Eating disorder inventory-3: Referral form manual. Lutz, Florida, Psychological Assessment Resources, 2004.

12. Sira N, Pawlak R. Prevalence of overweight and obesity, and dieting attitudes among Caucasian and African American college students in Eastern North carolina: A cross-sectional survey. Nutrition Research and Practice, 2010, 4:36-42.

13. Sassaroli S, Ruggiero GM. The role of stress in the association between low self-esteem, perfectionism, and worry, and eat- ing disorders. International Journal of Eating Disorders, 2005, 37:135-141.

14. Freedman DS et al. Relation of body mass index and waist-toheight ratio to cardiovascular disease risk factors in children and adolescents: the Bogalusa Heart Study. American Journal of Clinical Nutrition, 2007, 86:33-40.

15. Savva SC et al. Waist circumference and waist-to-height ratio are better predictors of cardiovascular disease risk factors in children than body mass index. International Journal of Obesity and Related Metabolic Disorders, 2000, 24:1453-1458.

16. Goran MI, Gower BA. Relation between visceral fat and disease risk in children and adolescents. American Journal of Clinical Nutrition, 1999, 70:1495-1565.

17. Lazarou C, Soteriades ES. Children's physical activity, TV watching and obesity in Cyprus: the CYKIDS study. European Journal of Public Health, 2010, 20:70-77.

18. Bathrellou E et al. Physical activity patterns and sedentary behaviors of children from urban and rural areas of Cyprus. Central European Journal of Public Health, 2007, 15:66-70.

19. Nelson $\mathrm{MC}$ et al. Longitudinal and secular trends in physical activity and sedentary behaviour during adolescence. Pediatrics, 2006, 118:e1627.

20. Jones DC, Vigfusdottir TH, Lee Y. Body image and the appearance of culture among adolescent girls and boys: an examination of friend conversations, peer criticism, appearance magazines, and the internalization of appearance ideals. Journal of Adolescent Research, 2004, 19:323-339.

21. Dobmeyer AC, Stein DM. A prospective analysis of eating disorder risk factors: drive for thinness, depressed mood, maladaptive cognitions, and ineffectiveness. Eating Behaviors, 2003, 4:135-147.

22. Joiner TE Jr, Heatherton TF, Keel PK. Ten-year stability and predictive validity of five bulimia-related indicators. American Journal of Psychiatry, 1997, 154:1133-1138.

23. McCarthy HD, Ellis SM, Cole TJ. Central overweight and obesity in British youth aged 11-16 years: cross sectional surveys of waist circumference. British Medical Journal, 2003, 326:624. 